\title{
PROFIL PENYAKIT SKABIES PADA PASIEN YANG BEROBAT DI WILAYAH KERJA PUSKESMAS KAMONJI TAHUN 2018
}

\author{
Salma Suciaty $^{1^{*}}$, Seniwaty Ismail ${ }^{1}$, Julaika ${ }^{1}$ \\ ${ }^{1}$ Program Studi Pendidikan Dokter, Fakultas Kedokteran Universitas Alkhairat, Jl. Diponegoro No. 39 \\ Palu 94221, Sulawesi Tengah, Indonesia \\ *Corresponding author: Telp: +628114536960email: salmah.suciaty@yahoo.co.id
}

\begin{abstract}
ABSTRAK
Skabies masih menjadi masalah kesehatan di Dunia dan di Indonesia, mengenai hampir semua golongan usia, ras dan kelompok sosial ekonomi. Penderita di kota Palu masih cukup tinggi, terutama di wilayah kerja Puskesmas Kamonji. Akibatnya penderita merasa kurang nyaman sehingga dampaknya dapat menganggu psikososialnya, oleh karena itu dilakukan promosi kesehatan untuk menurunkan prevalensi skabies di Kota Palu yaitu di wilayah kerja Puskesmas Kamonji. Penelitian bertujuan untuk mengetahui gambaran penderita skabies berdasarkan usia, jenis kelamin, tingkat pendidikan, tingkat hygiene, dan riwayat keluarga penderita skabies yang datang berobat di wilayah kerja Puskesmas kamonji. Metode penelitian ini dilakukan dengan metode Deskriptif Kategorik dan mengunakan cross sectional. Pengumpulan data dilakukan menggunakan wawancara kuesioner dan checklist tingkat pengetahuan kepada pasien yang telah di diagnosis menderita skabies oleh dokter. Hasil menunjukkan gambaran penderita terbanyak pada kelompok usia yaitu pada usia 11-16 tahun (45,9\%), jenis kelamin terbanyak pada laki-laki (83,8\%), tingkat pendidikan terbanyak yaitu SMP (56,8\%), hygiene riwayat kebersihan diri (mandi) $(24,3 \%)$, riwayat menganti pakaian $(62,2 \%)$, riwayat kebersihan seprei dan tempat tidur yang kurang $(70,3 \%)$, riwayat keluarga $(40,5 \%)$. Sebagai kesimpulan penderita sabies paling banyak pada kelompok usia 11-16 tahun, jenis kelamin laki-laki, tingkat pendidikan SMP, status hygiene lebih banyak pada riwayat kebesihan seprei yang kurang, riwayat kebersihan diri(mandi)2x sehari yang rendah dan tidak ada riwayat keluarga.
\end{abstract}

Kata Kunci: Skabies, Pasien, Puskesmas Kamonji

\section{ABSTRACT}

Scabies is still a health problem in the world and Indonesia, affecting almost all age groups, races, and socioeconomic groups. Patients in the city of Palu are still quite high, especially in the working area of the Kamonji Health Center. As a result, sufferers feel uncomfortable so that the impact can disrupt their psychosocial, therefore health promotion is carried out to reduce the prevalence of scabies in Palu City, namely in the working area of the Kamonji Health Center. This study aims to determine the description of scabies sufferers based on age, gender, education level, hygiene level, and family history of scabies patients who come for treatment in the working area of the Kamonji Health Center. The method of this research is a descriptive categorical method and using cross-sectional. Data was collected using questionnaire interviews and a checklist of knowledge levels to patients who had been diagnosed with scabies by doctors. The results show that the most patients in the age group are at the age of 11-16 years (45.9\%), the most gender is male (83.8\%), the highest level of education in junior high school (56.8\%), history of hygiene personal hygiene (bathing) (24.3\%), history of changing clothes (62.2\%), history of poor bed linen and bed hygiene (70.3\%), family history (40.5\%). In conclusion, the highest number of patients with scabies is in the age group 11-16 years, male gender, junior high school education level, hygiene status is more in the history of poor bed linen hygiene, low personal hygiene history (bathing) $2 x$ a day and no family history.

Keywords: Scabies, Patient, Kamonji Health Center 


\section{PENDAHULUAN}

Skabies adalah penyakit kulit yang disebabkan oleh investasi dan sensitisasi terhadap sarcoptes skabiei varian hominis yang membentuk terowongan pada lapisan stratum korneum dan staratum granulosum yang ditandai dengan keluhan gatal, terutama pada malam hari. ${ }^{1,2}$

Angka kejadian penyakit skabies menutut WHO diperkirakan 300 juta kasus diseluruh dunia yang terkena skabies. ${ }^{3}$ Di Brazil pada tahun 2013 prevalensi skabies mencapai $18 \%,{ }^{4}$ di Afrika barat tahun 2013 sebesar 28,33\%, ${ }^{5}$ di Nigeria tahun 2013 yaitu 13,55\%, ${ }^{6}$ di Malaysia pada tahun 2013 sebanyak 31\%, ${ }^{7}$ sedangkan di India pada tahun 2013 sebesar 20,4\%. ${ }^{8}$

Di Indonesia prevalensi skabies masih cukup tinggi, yaitu sebesar 5,60-12,95\% dan skabies menduduki urutan ketiga dari 12 penyakit kulit tersering ${ }^{9}$, di Papua prevalensi skabies sebesar $80 \% .{ }^{10}$ di Jawa Barat $2,7 \%{ }^{11}$

Di Sulawesi Tengah, jumlah kasus scabies pada tahun 2013 jumlah kasus 4.568, tahun 2014 jumlah kasus 3.648, tahun 2015 jumlah kasus 5.079 dan tahun 2016 jumlah kasus 3.104. ${ }^{12}$, Untuk kota Palu, jumlah kasus scabies pada tahun 2013 ialah 304, tahun 2014 yaitu 1.521, tahun 2015 sebanyak 961 dan pada tahun 2016 yaitu sebanyak 547 kasus skabies. ${ }^{13}$, Dan di wilayah kerja Puskesmas Kamonji pada tahun 2013 yaitu 348, tahun 2014 sebanyak 284, tahun 2015 yaitu sebanyak 365, dan pada tahun 2016 sebanyak 229 kasus scabies. ${ }^{14}$

Beberapa faktor yang dapat membantu penyebaran penyakit skabies antara lain sosial ekonomi yang rendah, higiene yang buruk, hubungan seksual dengan berganti-ganti pasangan, diagnosis yang salah, demografi, dan ekologi. Beberapa literatur melaporkan, skabies bisa menggambarkan sebuah ancaman di suatu institusi, seperti asrama, penjara, panti asuhan, panti jompo, dan fasilitas perawatan jangka panjang.

\section{METODOLOGI}

Metode penelitian yang digunakan adalah metode Deskriptif Kategorik dengan pendekatan cross sectional di Wilayah Kerja Puskesmas Kamonji tahun 2018.
Subyek Penelitian adalah pasien yang datang berobat jalan di Wilayah Kerja Puskesmas Kamonji pada tahun 2018 yang di diagnosis menderita skabies oleh dokter umum yang memenuhi kriteria penelitian inklusi dan ekslusi. Penelitian ini bersifat deskriptif kategorik, berdasarkan perhitungan dengan rumus Teknik Slovin diperoleh jumlah sampel sebanyak 37 orang penderita scabies. Selain itu cara pengambilan sampel dilakukan dengan melihat data subyek pada medical record tahun 2018 dan metode pengambilan mengunakan cara "consecutive sampling" yaitu penderita skabies yang berobat di Wilayah Kerja Puskesmas Kamonji.

Analisis data menggunakan deskriptif Kategorik dan Numerik dengan hasil berupa frekuensi dan presentase (proporsi) yang dapat disajikan dalam bentuk tabel maupun grafik. Data yang diperoleh terdiri dari profil demografi (usia, Jenis kelamin), tingkat pendidikan, Hygene, sanitasi lingkungan, Riwayat keluarga.

\section{HASIL DAN PEMBAHASAN}

\section{HASIL}

\section{Gambaran Penderita Scabies Berdasarkan Usia}

Didapatkan hasil dari 37 pasien scabies yang memenuhi kriteria penelitian terbanyak ditemukan pada kelompok usia11-16 tahun sebanyak (45,9\%). Gambaran penderita scabies berdasarkan usia dapat dilihat dalam tabel berikut ini :

Tabel 1. Gambaran pasien scabies berdasarkan usia yang berobat di Wilayah Kerja Puskesma Kamonji tahun 2018.

\begin{tabular}{ccc}
\hline Usia & Frekuensi & Presentase \% \\
\hline $11-16$ tahun & 17 & 45.9 \\
$17-25$ tahun & 8 & 21.6 \\
$46-55$ tahun & 3 & 8.1 \\
$>56$ tahun & 9 & 24.3 \\
\hline Total & 37 & 100.0 \\
\hline
\end{tabular}

2. Gambaran Penderita Scabies Berdasarkan Jenis Kelamin

Didapatkan hasil dari 37 pasien scabies yang memenuhi kriteria penelitian terbanyak 
ditemukan pada jenis kelamin laki-laki $(83,8 \%)$ dari pada perempuan $(16,2 \%)$. Gambaran penderita penderita scabies berdasarkan jenis kelamin dapat dilihat pada tabel berikut ini :

Tabel 2. Gambaran pasien scabies berdasarkan jenis kelamin yang berobat di Wilaya Kerja Puskesmas Kamonji tahun 2018.

\begin{tabular}{ccc}
\hline Jenis Kelamin & Frekuensi & Persentase $\%$ \\
\hline Laki-laki & 31 & 83.8 \\
Perempuan & 6 & 16.2 \\
\hline Total & 37 & 100.0 \\
\hline Uji Deskriptif & &
\end{tabular}

\section{Gambaran Penderita Scabies Berdasarkan Tingkat Pendidikan}

Didapatkan hasil dari 37 pasien scabies yang memenuhi kriteria penelitian terbanyak ditemukan pada tingkat pendidikan SMP $(56.8 \%)$ dan terendah ditemukan pada tingkat pendidikan SD yaitu sebanyak (13.5\%). Gambaran penderita scabies berdasarkan tingkat pendidikan dapat dilihat pada tabeltabel berikut ini :

Tabel 3. Gambaran pasien scabies berdasarkan tingkat pendidikan yang berobat di Wilayah Kerja Puskesmas Kamonji tahun 2018.

\begin{tabular}{ccc}
\hline Tingkat & Frekuensi & Peresentase \% \\
Pendidikan & & 5.4 \\
Tidak sekolah & 2 & 13.5 \\
SD & 5 & 56.8 \\
SMP & 21 & 24.3 \\
SMA & 9 & 100.0 \\
\hline Total & 37 &
\end{tabular}

Uji Deskriptif

\section{Gambaran Penderita Scabies Berdasarkan} Tingkat Hygiene

Didapatkan hasil dari 37 pasien scabies yang memenuhi kriteria penelitian berdasarkan tingkat hygiene seperti mandi, menganti pakaian, kebersihan tempat tidur (seprei). Dari hasil yang didapatkan mandi (24.3\%) dan yang tidak mandi $(75.7 \%)$, hasil yang mengganti pakaian $(62.2 \%)$, yang tidak mengantin pakaian $(37.8 \%)$ dan kebersihan tempat tidur(seprei) $(70.3 \%)$ yang dipakai bersama-sama dan yang tidak mengunakan seprei bersama-sama (29.7\%). Gambaran penderita scabies berdasarkan tingkat hygiene dapat dilihat pada tabel berikut ini:

Tabel 4. Gambaran penderita scabies berdasarkan tingkat hygiene

\begin{tabular}{|c|c|c|}
\hline Tingkat Hygiene & Frekuensi & Presentase \% \\
\hline Riwayat Kebersihan & & \\
\hline Diri (Mandi) 2x sehari & & \\
\hline $\mathrm{Ya}$ & 9 & 24.3 \\
\hline Tidak & 28 & 75.7 \\
\hline $\begin{array}{l}\text { Riwayat Menggan } \\
\text { Pakaian 2x sehari }\end{array}$ & & \\
\hline Ya & 23 & 62.2 \\
\hline Tidak & 14 & 37.8 \\
\hline
\end{tabular}

Riwayat Kebersihan

Seprei dan tempat

tidur digunakan

bersama-sama

$\begin{array}{lll}\text { Ya } & 26 & 70.3\end{array}$

Tidak $\quad 11 \quad 29.7$

$\begin{array}{lll}\text { Total } & 37 & 100.0\end{array}$

\section{Gambaran penderita scabies Berdasarkan} Riwayat keluarga

Didapatkan hasil dari 37 pasien scabies yang memenuhi kriteria penelitian terbanyak pada yang tidak memiliki riwayat keluarga (40.5\%), sedangkan yang terenda ditemukan pada penderita yang memiliki riwayat keluarga (59.5\%). Gambaran penderita scabies berdasarkan Riwayat Keluarga dapat dilihat pada tabel berikut ini:

Tabel 5. Gambaran penderita scabies berdasarkan riwayat keluarga

\begin{tabular}{lll}
\hline Riwayat Keluarga & Frekuensi & Presentase\% \\
\hline Ya & 15 & 40.5 \\
Tidak & 22 & 59.5 \\
\hline Total & 37 & 100.0 \\
\hline
\end{tabular}

\section{PEMBAHASAN}

\section{Menurut Gambaran Usia}

Dari hasil penelitian menurut usia terhadap kejadian scabies adalah tertinggi kelompok masa usia di bawah umur yaitu 1116 tahun. sejalan dengan penelitian Fauziah dkk tahun 2013 yaitu kelompok terbanyak adalah usia 11-17 tahun yaitu sebanyak 79 
orang $(39,69 \%)$ dan juga sejalan dengan penelitian yang dilakukan Made Erik S.G dkk tahun 2012 yaitu kelompok usia terbanyak menderita skaies yaitu 15-24 tahun sebanyak 12pasien $(29,26 \%)$. Lalu juga sejalan dengan pengumpulan data kelompok studi Dermatologi Anak Indonesia (KSDAI) tahun 2001 dari 9 rumah sakit di 7 kota besar di Indonesia, diperoleh sebanyak 892 penderita scabies dengan insiden tertinggi pada kelompok usia (5-14 tahun) sebesar 54,6\%

Umur merupakan salah satu sifat karakteristik yang sangat utama karena umur juga mempunyai hubungan yang erat dengan keterpaparan. Dengan demikian, dapat dimengerti bahwa adanya perbedaan pengalaman terhadap penyakit menurut umur, mempunyai pengaruh yang berhubungan dengan adanya perbedaan dalam proses kejadian pathogenesis, maupun adanyaperbedaan pengalaman terhadap penyakit tertentu.

\section{Menurut Gambaran Jenis Kelamin}

Dari hasil penelitian menurut jenis kelamin terhadap kejadian skabies adalah tertinggi pada jenis kelamin laki-laki yaitu $(83,8 \%)$ sejalan dengan penelitian yang dilakukan Farnisyah F pada tahun 2012 di RSUD Labuang Baji Makassar menemukan kejadian skabies lebih banyak pada laki-laki $(52,3 \%)$ daripada perempuan $(47,7 \%)$ dan juga sejalan dengan penelitian yang dilakukan Fauziah dkk 2015 dimana didapatkan penderita skabies terbanyak pada laki-laki sebanyak $150 \quad(75,6 \%)$ dibandingkan perempuan $49(24,62 \%)$.

Menurut Muin, orang dengan jenis kelamin perempuan akan lebih kecil resiko terpapar skabies karena perempuan cenderung lebih selalu merawat dan menjaga penampilan, dengan begitu kebersihan diri perempuan juga lebih terawat. Sedangkan laki-laki cenderung tidak memperhatikan penampilan diri, hal itu tentunya akan berpengaruh terhadap perawatan kebersihan diri, dan kebersihan diri yang buruk tersebut yang akan sangat berpengaruh terhadap kejadian skabies.

\section{Menurut Gambaran Tingkat Pendidikan}

Dari hasil penelitian menurut tingkat pendidikan menunjukan bahwa presentase tertinggi sebesar 17 (56.8\%) ditemukan pada tingkat pendidikan yang rendah yaitu sekolah menengah pertama (SMP), sejalan dengan penelitian yang dilakukan Saleha S, dkk pada tahun 2013 menemukan kejadian skabies lebih banyak pada tingkat pendidikan Tsanawiyah (Mts) yaitu 68 (58,1\%), dan juga sejalan dengan penelitian yang dilakukan Achmad $\mathrm{H}$. tahun 2010 yaitu lebih banyak pendidkan SMP (70\%)

Dari hasil penelitian yang ditemukan peneliti, jumlah kasus penderita skabies yang berobat di Wilayah Kerja Puskesmas Kamonji yang cukup banyak mungkin dikarenakan pemahaman penderita yang kurang akibat rendahnya tingkat pendidikan sehingga kurang paham mengenai masalah penyakit skabies. Hal ini sesuai dengan teori Notoatmodjo, yang mengatakan bahwa semakin tinggi pendidikan formal yang dicapai maka semakin baik pula proses pemahaman seseorang dalam menerima informasi sehingga mampu menyesuaikan diri dengan lingkungannya melalui proses perkembangan diri untuk meningkatkan pengetahuan, keterampilan, dan sikap yang mestinya untuk mencegah perkembangan penyakit scabies.

\section{Menurut Gambaran Tingkat Hygiene}

Dari hasil penelitian menurut tingkat hygiene kebersian diri (mandi) ditemukan lebih banyak sampel yang jarang membersikan diri, sedangkan menurut riwayat mengganti pakaian ditemukan sampel yang sering berganti pakaian, dan menurut riwayat kebersihan seprei lebih banyak yang digunakan untuk tidur bersama-sama. Sejalan dengan penelitian Rima Semiarty dkk tahun 2013 didapatkan tingkat hygiene yang tidak baik sebanyak (44,1\%). Higiene atau kebersihan adalah upaya untuk memelihara hidup sehat yang meliputi kebersihan pribadi, kehidupan bermasyarakat, dan kebersihan kerja. 


\section{Menurut Gambaran Riwayat Keluarga}

Dari hasil penelitian menurut riwayat keluarga terhadap kejadian skabies adalah terbanyak memiliki riwayat keluarga dengan presentase sebesar (40.5\%), sejalan dengan penelitian yang dilakukan Sawitri, dkk pada tahun 2009 menemukan kejadian skabies lebih banyak pada penderita yang memiliki riwayat keluarga $26(57,7 \%)$, dan juga sejalan dengan penelitian yang dilakukan Farnisyah $\mathrm{F}$ pada tahun 2012 di RSUD Labuang Baji Makassar menemukan kejadian skabies yaitu 60 kasus memiliki riwayat keluarga dengan presentase sebesar $(54,1 \%)$

Penyakit ini meyerang manusia secara kelompok, sehingga dalam sebuah keluarga biasanya seluruh anggota keluarga terkena infeksi. Begitu pula dalam sebuah perkampungan yang padat penduduknya, sebagian besar tetangga yang berdekatan akan diserang oleh tungau tersebut. Didalam kelompok, mungkin akan ditemukan individu yang hiposensitisasi, walaupun terinfeksi oleh parasit sehingga tidak menimbulkan keluhan klinis akan tetapi menjadi pembawa/carrier bagi individu lain.

\section{KESIMPULAN}

Berdasarkan hasil penelitian dari 37 pasien penderita skabies di Wilayah kerja puskemas kamonji Palu tahun 2018 tentang profil penderita skabies yang berobat di Wilayah kerja Puskesmas Kamonji Tahun 2018, maka kesimpulannya sebagai berikut:

1. Gambaran penderita skabies berdasarkan usia. Kelompok usia yang terbanyak yaitu kelompok usia remaja awal 11-16 tahun

2. Gambaran penderita skabies berdasarkan jenis kelamin. Jenis kelamim pasien skabies yang terbanyak yaitu laki-laki

3. Gambaran penderita skabies berdasaerkan tingkat pendidikan. Tingkat pendidkan pasien skabies yang terbanyak yaitu pada tingkat pendidikan Sekolah Menegah Pertama (SMP)

4. Gambaran penderita skabies berdasarkan tingkat hygiene.

5. Gambaran penderita skabies berdasarkan riwayat keluraga. Pasien skabies memiliki riwayat keluarga dengan penyakit skabies yaitu sebesar $40.5 \%$

\section{DAFTAR PUSTAKA}

1. Ariza L., Walter B., Worth C. Brockmann, Weber M.L., \& et al. (2012). Investigation of a scabies outbreak in kindergarten in constance germany. Eur J. Clin Microbial Infect Dis (DOI) 10,1007-1096.

2. Azizah I.N. \& Setiyowati W. (2011). Hubungan tingkat pengetahuan ibu pemulung tentang personal hygiene dengan kejadian skabies pada balita di tempat pembuangan akhir kota semarang. Dinamika Kebidanan 1, 1-5.

3. Bandi K.M. \& Saikumar C. (2012). Sarcoptic mange-a zoonotic ectoparasitic skin disease. Journal of Clinical and Diagnostic Research 4839, 1-2.

4. Baur B, Sarkar J, Manna N, et al.. The pattern of dermatological disorder among patient Is attending the skin O.P.D of a tertiary care hospital in Kolkata India. 2013, Journal of Dental and Medical Science (diakses 24 Januari 2017) From :http://iosrjournals.org/iosjdms/.

5. Barker F. Scabies management. Paediatr Child Health. 2010;6:775-7.

6. Beegs J, ed. 2012. Scabies Prevention and Control Manual. Michigan: Michigan Departement of Community Health Scabies Prevention and Control Manual.

7. Buku Arsip Jumlah Penderita Tahunan Rumah Sakit Umum Daerah Undata Palu dan Rumah Sakit Umum Anutapura Palu, 2016.

8. Currie B.J, et al. 2010. Clinical Microbiology Reviews: Problems in Diagnosting Scabies, a Global Disease in Human and Animal Populations.

9. Departemen Kesehatan Republik Indonesia. 2013. Sistem Kesehatan Nasional. Jakarta.

10. Dinas Kesehatan Kota Padang. 2010. Profil Kesehatan Kota Padang 2010.

11. Djuanda, Adhi. T.N (Ed),. Bagian Ilmu Penyakit Kulit dan Kelamin. Edisi keempat. Fakultas Kedokteran Universitas Indonesia, 2013. 
12. Emodiet, I.J. et al., Skin disease among sttending the out patient clinic of the University of Nigeria teaching hospital, Enug. 2013. (diakses 22 Januari 2017)From:

http://www.ncbi.nlm.nih.gov/pmc/articles/ PMC.

13. Gunawan IMES. Profil skabies di Poliklinik Kulit dan Kelamin RSU Prof. Dr. R. D. Kandou Manado periode Januari - Desember 2012 [Skipsi]. Manado: FK Unsrat, 2013.

14. Gunning, K, Pipitt, K, Kiraly, B. 2012. 'Pediculosis and scabies : A Treatment Update. American Family Physician, Vol. 86, No. 6, Hal. 535. (diakses 27 Januari 2017) From : Http://www.aafp.org/2 012/0915/p535.html.

15. Zayyid, M.M. et al.,. Prevalence of scabies and head lice among children in a welfare home in Pulau Pinang Malaysia (serial online) 2013. 